\title{
LA IDEA DE EUROPA EN LA CULTURA FRANQUISTA 1939-1962
}

por

\author{
MIGUEL ÁNGEL RUIZ CARNICER \\ Universidad de Zaragoza.
}

RESUMEN: Uno de los rasgos más sobresalientes del franquismo es su aislamiento internacional debido tanto al discurso nacionalista del régimen como al recbaro exterior tras la derrota de los fascismos en la segunda guerra mundial. Sin embargo, el tema de las relaciones entre España y Europa estuvo presente a lo largo de la evolución intelectual y politica del régimen. Este articulo pretende mostrar cómo va evolucionando la visión que sobre este problema se tiene en las álites intelectuales del franquismo y los debates en torno a ello, siempre en función de la justificación y supervivencia del sistema. De becho, frente a la Europa democrática y liberal se opondrá, una vez eclipsado el sueño de una Europa fascista, la imagen de una Europa católica, fuertemente enraizada en unos valores tradicionales identificados con la auténtica esenita europea, que sólo España realmente habia sabido guardar de los combates de la modernidad. Esta atención al tema europeo mostraba, por un lado, la preocupación de los vencedores de la guerra civil por la imagen que se tenía de España en el resto de Europa, y por otra, su profundo miedo a aceptar con todas sus consecuencias la berencia intelectual y cultural de la Europa contemporánea.

PalABRAS Clave: Franquismo. Cultura. España. Europa. Historia intelectual. Relaciones Espana-Europa.

ABSTRACT: One of the main features of Franco's regime is bis international isolation due to both bis nationalist discourse and the political rejection in Europe of the last stronghold of defeated fascism. However, the issue of relations between Europe and Spain was a key question alongside the regime's intellectual and political evolution. This article tries to explain the development and disputes of the francoist intelligentsia over this matter. The common goal was the justification and survival of Franco's system. Firstly, asserting the Nazi project of a fascist Europe; aftenwards, vindicating a Catholic Europe and its traditional values in oppasition to the reality of a liberal and democratic Europe in the postwar years. The relevance of the debate shows, on the one hand, the concern of the victors of the civil war with the image of Spain in Europe and, on the other, its deep fear of accepting the full consecuences of the intellectual and cultural beritage of Contemporary Europe.

KEY WORDS: Francoism. Culture. Spain. Europe. Intellectual History. Spain-Europe relations.

Hitpania, LVIII/2, núm. 199 (1998) 679-701 
En 1962 tenía lugar un hecho sorprendente para muchos: España pedía formalmente la adhesión al Mercado Común Europeo. Una adhesión que, lógicamente, no tenía posibilidad alguna de prosperar, dadas las características del régimen político español. Actos como la reunión del Movimiento Europeo en Munich en ese mismo año y sus consecuencias para los asistentes a su regreso evidenciaron lo vano de este intento. Sin embargo, en esta petición española había algo más que una operación de imagen, o la búsqueda de la plena unormalización» de las relaciones exteriores de la España franquista: era el reconocimiento formal y oficial de que el destino económico, social y político de España estaba unido necesariamente a Europa y, concretamente, al proyecto de construcción europea que en esos años se aglutinaba en torno al Mercado Común.

Antes de este momento - límite de nuestro trabajo- tenemos un largo periodo que comienza con la sublevación del 18 de julio de 1936, inicio de una destructiva guerra civil de claro contenido social y político que iba a terminar con la victoria del bando acaudillado por el general Franco, uncido al carro de los fascismos, en ese momento en alza en toda Europa. Uno de los leit-motiv en la justificación del alzamiento va a ser la necesidad de librar a España de la influencia de doctrinas extranjeras, una de las causas, según los insurgentes, del deterioro de los ivalores morales» españoles '.

Paradójicamente, la política del Nuevo Estado va a estar en todo momento indisolublemente relacionada con la evolución del entorno europeo y occidental, en primer lugar por la propia dinámica de la guerra mundial y posteriormente por el aislamiento internacional del régimen. Sea como fuere, Europa era punto de referencia inexcusable de la cultura del franquismo, fuera «en positivo" o "en negativo".

Ciertamente, hay problemas para caracterizar con precisión la naturaleza de una supuesta "cultura franquista», ya que nunca el régimen intentó ni dio paso alguno para crear algo digno de tal nombre; de becho, el nacimiento del régimen (y, en gran medida, su evolución posteriot) se caracteriza por un fuerte carácter antiintelectual, tomado de la tradición del pensamiento reaccionario español y de las doctrinas fascistas triunfantes en esos momentos en Europa. De ahí la ausencia de deseo alguno de construir una cultura propia. El mayoritario apoyo de los intelectuales al bando republicano en la guerra era bastante elocuente ${ }^{2}$. Para caracterizar la vida cultural del franquismo ha quedado acuñada la imagen de "páramo cultural» por la practica totalidad de los autores, recientemente F. Savater o G. Morán ${ }^{3}$. Esto no obsta para que podamos hablar

\footnotetext{
1 VIVER PI-SUNYER, C., «Aproximació a l'ideologia del franquisme en l'etapa fundacional del régimy, en Papers. Revista de sociología n. ${ }^{\circ} 14$ (1980), p. 26.

2 CARR, R. y FUSI, J. P., Epaña de la dictadura a la democratia, PJaneta, Barcelona, 1979, p. 133.

3 SAVATER, F., «Angeles decapitados. La desertización cultural bajo el franquismon, Claves de Razón Práctica, n. 59 (enero/febrero 1996) y MORÁN, G., El maestro en el erial Ortegay Gasset y la cultura del franquismo, Tusquest, Barcelona, 1998. Este último trabajo, dado el peculiar estilo de Morán ha despertado numerosas y sonoras criticas. Dejando de lado la frivolidad con la que se subestiman complejos personajes del mundo filosófico y cultural del franquismo, este traba-
}

Hipania, LVIII/2, núm 199 (1998) 679-701 
de una literatura, filosofía, arte, etc. Ligados al franquismo como vivencia o marco, pero muy escasamente como producto mismo de las fuerzas que éste pudiera haber alentado. El régimen sí que aparecerá como acicate o protector de las manifestaciones culturales que adquirían un perfil propagandístico o podían ser útiles para la imagen exterior del régimen. Ese será el caso del arte abstracto en los años cincuenta y sesenta 4 .

Al hablar de "cultura franquista» aquí aludimos al conjunto de ideas, representaciones y valores que van a llenar de contenido al régimen en sus manifestaciones más intelectuales, ligadas de una manera concluyente a los distintos grupos político-ideológicos que integraron el bando franquista desde el inicio de la guerra y cuya actuación fue también decisiva en el desgaste de la Segunda República; en definitiva, los que aportaron el soporte ideológico y el personal político al régimen franquista desde sus inicios. Estos grupos - nos resistimos a darles la caracterización de "familias»-n no tenían una procedencia común en el campo de las ideas pero les unía el compartir los valores encarnados por Franco y por el bando antirepublicano.

Sin embargo, independientemente de estas coincidencias, cada grupo va a tener no sólo distintas raíces, sino proyectos políticos divergentes en muchos aspectos, en la medida en que todos intentaban capitalizar y definir según su propio interés el régimen franquista; en lo que había consenso era en su conservación como útil instrumento para sus fines, pero no en el modo de hacerlo.

El choque entre las distintas líneas políticas que confluyen en el régimen va a ser el marco principal en el que se va a engastar el tema de Europa y la reflexión sobre ésta y sus relaciones con España; no va a ser el único, en la medida en que irán apareciendo los primeros círculos europeístas, al margen de la cultura oficial unas veces y otras a partir de instituciones u organizaciones de carácter oficioso o religioso; asimismo, el nombre sólo de Europa evocaba la libertad política, cultural y vital para cada vez una mayor porción de una juventud formada en un ambiente mediocre y cerrado al exterior ${ }^{5}$.

La actitud de la Intelligentzia franquista respecto a Europa va a estar también muy relacionada con la propia coyuntura del régimen, así como con la lucha por la primacía misma entre sus distintos componentes. De esta manera, los

jo supone un intuititvo y apasionado estudio desde una perspectiva que acietta en teatratar el ambiente de la época aún a pesar de sus enormes lagunas bibliográficas, de su escasa erudición y de la abundancia de sal gorda. En todo caso, un libro necesario que pide urgentemente nuevos aportes de más calibre y pluma más serena.

4 UREǸ, G., Las vanguardias antiticas en la postguerra española, 1940-1959, Istmo, Madrid, 1982, pp. $28-29$

5 Recientemente han aparecido en el mercado dos obras de Antonio Moreno Juste, autor especializado en las relaciones entre España y europa durante el siglo XX, que lamentablemente no han podido ser integradas en este trabajo dado su fecha de aparición; se trata de Franquismo y construcción europea (1951-1962). Anhelo, necesidad y realidad de la aproximación a Europa, Madrid, 1998 y España y el proceso de construcción europea, 1945-1997, A tiel, Barcelona, 1998. A ellas remitimos para enmarcar esas refiexiones en un contexto más amplio.

Hippania, LVIII/2, núm 199 (1998) 679-701 
años inicales del franquismo destacan por un claro predominio - al menos formal- de Falange y sus allegados, para posteriormente dejar paso a los hombres ligados a la Asociación Católica Nacional de Propagandistas y a Acción Católica. En esos mismos años otros católicos cercanos a la asociación religiosa Opus Dei iban consolidándose como un sector en alza, especialmente a través del Consejo Supetior de Investigaciones Científicas y el acceso a las cátedras universitarias, al calor de la gestión del Ministro Ibañez Martín ${ }^{~}$. Sin embargo, el protagonismo político de los hombres de la Obra se va a dar a partir del giro político-económico de 1957-59. Estos serán los hombres que llamarán a la puerta del Mercado Común.

Otras líneas de pensamiento y comportamiento político se entremezclan con estas dominantes a lo largo del periodo, por ejemplo, los mal llamados «falangistas liberales", hombres que por su sentido humanista y por su brillante trayectoria personal y profesional van a adquirir un peso evidente entre la intelectualidad española. Estos van a ir en ocasiones de la mano de otros hombres provenientes del campo católico (ACNdP fundamentalmente) que van a sostener también una política de mayor apertura intelectual, como es el caso de Joaquín Ruiz Giménez desde el Ministerio de Fducación Nacional.

Muchos autotes han abordado ya las características, evolución $\mathrm{c}$ interrelación de estas fuerzas en el período, especialmente por lo que hace a las luchas por el poder ${ }^{7}$ y también, aunque en menor medida, en lo relativo a su producción intelectual y política ${ }^{8}$. De ahí que nos limitemos a constatar la existencia de estos grupos como auténticos coautores de lo que se podría llamar una «cultura» o "cosmogonía» franquista. Limitémonos a indicar que a veces la identificación de las personas con sus grupos de origen plantea no pocas dificultades, dado que no son en absoluto estructuras operativas y jetarquizadas, sino uredes» de un cierto clientelismo científico, intelectual y de intereses, que siendo muy fuerte en ocasiones, era a la vez ambivalente y cambiante.

Las elaboraciones intelectuales sobre el tema de Europa y la telación de España con el resto del continente van a estar pues definidas por esta doble coordenada, la de las específicas raíces ideológicas de los grupos que conforman la práctica politica del régimen, con su lucha por el control de parcelas de poder en el seno de éste y las necesidades y actitudes que en política exterior debía de adoptar el régimen para lograr su supervivencia y perduración.

6 Pasamar Alzuria, G., «Oligarquias y clientelas en el mundo de la investigación científica: El Consejo Superior en la Universidad de posguerras, en CARRLiRAS ARSS, J. J. y RUI'C CARNICER, M. A. (eds.), La Universidad española bajo el régimen de Franco (1939-1975), Institución Fernando el católico, Zaragoza, 1991.

7 TUSELL, J., Franco y los católicos. La politica interior española entre 1945 y 1957, Alianza Universidad, Madrid, 1984.

8 PASAMAR ALZURIA, G., Historiografía e ideologia en la postguerra española: la ruptura de la tradición Hberal, Prensas Universitarias de Zaragoza, Zaragoza, 1991.

Hispania, LVIIL/2, núm. 199 (1998) 679-701 


\section{ESPAÑA EN LA EUROPA DEL EJE}

Sería muy difícil incluir dentro de las coordenadas del europeísmo al uso el entusiasmo de determinados sectores del régimen por una Europa hegemonizada por la Alemania de Hitler y secundada en esta tarea por la Italia de Mussolini y la España de Franco. Sin embargo, el nuevo Estado apostará por basar su imagen en el grupo político - Falange- que mejor se adecuaba a las potencias del Eje, las que también habían colaborado económica y militarmente en el triunfo del bando franquista en la guerra civil, y que aparecian como triunfantes en las trincheras de Europa. Detrás de esta opción no estaba sino la sumisión interesada a los planes de Alemania, expresados con cierta insistencia en su propaganda sobre la creación de una «nueva europa continental».

Falange aparecía como la fuerza hegemónica en el primer franquismo; sin embargo el problema era la realidad que se escondía tras la referencia a FET y de las JONS, dada su composición heterogénea, fruto del decreto de unificación, de la burocratización progresiva de la estructura del Movimiento y de la ausencia de una coherencia en el seno del partido único. Falange, con todo, tenía unos medios muy importantes en el terreno de la propaganda y la influencia política, pero no estaba avalado por el peso propio de sus integrantes, sino por el enorme aparato que se artículó en su entorno y que estará fundamentalmente en manos de las minotías falangistas de anteguerra y en católicos más o menos fascistizados. Estos últimos son los que progresivamente irán afirmándose conforme la posición del Eje sea más débil.

Desde el punto de vista político-cultural $\longrightarrow$ de epropaganda en la alta maneras, que dirian los jóvenes responsables de Escorial hay que citar la creación del Instituto de Estudios Políticos en septiembre de 1939 como auténtico brain trust de Falange", y con unos objetivos bien claros: «elaboración de una teoría política, colaboración en el proceso de redacción de leyes y nutrición de los cuadros superiores de la administracións ${ }^{10}$. En definitiva, se trataba de crear una escuela de política falangista que, sin embargo, no se va a consolidar en los términos previstos por la evolución bélica adversa a los intereses de los partenaires políticos de Falange en Europa. De ahí que, a partir ya de 1942 se puede hablar de una creciente orientación hacia lo que Elias Díaz ha llamado «fascismo católicon " ${ }^{1}$. El órgano de expresión del Instituto era la Revista de Estudios Políticor, revista que está lejos de ser una mera correa de transmisión de los intereses intelectuales del partido-burocracia, ya que enseguida desarrollará una cierta ambición intelectual demostrada en la variedad de temas políticos, jurídicos o sociológicos que se abordarán. Con todo, primó el objetivo de legitimar al régimen, desgajándolo precisamente del tronco del totalitarismo fascista. En esta

9 PAYNE, S. G., Falange. Historia del fascismo español S.A.R.P.E. Madrid, 1985, p. 217.

10 PASAMAR ALZURI, , G., Historiografia e ideologia..., p. 62.

11 DíAZ, F., Notas para una bistoria del pensamiento actual (1939-1973), EDICUSA, Madrid, 1974 , p. 33

Hipataia, LVIII/2, num 199 (1998) 679-701 
publicación vamos a encontrar una gran atención hacia lo que la revista misma llama «el problema de Europa».

Esta evolución del Instituto nos muestra la postura mayoritaria del personal falangista en los comienzos del régimen, dejando de lado iniciativas más personales --ese "guetto al revés» en palabras de Laín- - como es el caso de la revista Escorial, aunque también ésta esté claramente en la órbita del proyecto de una Europa hegemonizada por el orden nuevo del fascismo.

De hecho, se puede decir que una parte importante de la producción de pensamiento, historiografia y literatura está presidida por un no oculto afán por el triunfo del fascismo en Europa, compatible con ciertas reservas respecto a algunos rasgos del régimen nazi, fundamentalmente los excesos racistas (lo que no quiere decir que no exista un antisemitismo más o menos sutil en algunos autores) y el paganismo de algunas de sus manifestaciones. Lo que sí es cierto es que hay una disposición a justificar el compromiso del régimen en la construcción de esta Europa fascista. Un buen ejemplo de este propósito es el libro de Juan Beneyto España y el problema de Europa. Contribución a la Historia de la idea de imperio ${ }^{12}$, en el que el autor nos expone el pasado «imperial» de Espana, intentando presentar el "nuevo orden europeo» nazi como el marco ideal para su recuperación uniendo vocación europea e imperio. Parecidos pronunciamientos podemos encontrar en algunos editoriales de Escorial.

Otros autores, Llevados del mismo impulso, mostraban cómo la participación en el proyecto de la Europa fascista era una necesidad pues España debía asumir el papel de «tecristianizadora» de Europa, frente al «peligro protestante» inherente al predominio alemán, adelantando así la idea-fuerza que sobre el tema europeo predominará durante el período que tratamos en este trabajo: Europa como producto de la cristiandad y la cristiandad como única vía para la recuperación de la unidad del continente, en este caso compatible con la victoria alemana. La única alternativa a ésta sería el triunfo del "satánico bolchevismon, dada la debilidad de Francia e Inglaterra ${ }^{13}$.

Las señas de identidad europea se resumirían - según estas elaboraciones- en "tres columnas»: la civilización griega, el imperio romano y la cristiandad encarnada en la Iglesia. España coronaría este edificio por su «ejecutoria imperial en tiempos pasados, ahora redivivos» ${ }^{14}$. Esta será la clave de la postura posterior, una vez claras las escasas posibilidades de triunfo alemán tras la defección italiana, pasando de las posiciones pro-eje a las que se basaban en el carácter católico del régimen español como forma de diferenciarse de sus antiguos aliados, utilizando cierta ambigüedad que intentaba justificar a la luz

12 BENEYTO PÉREZ, J., España y el problema de Europa. Contribución a la Historia de la idea de imperio, Editora Nacional, Madrid, 1942.

13 CASTRo RIAL, J. M., «El problema de la realidad de Europa» en Revista de Estudios Poltticas $\mathrm{n}^{\circ} 12$ (noviembre-diciembre 1943 ).

14 AUNOS, E., "Las tres columnas de la unidad europea», en Revista de Estudios Politicos n. 11 (septiembre -octubre 1943).

Hilpania, LVIII/2, núm. 199 (1998) $679-701$ 
del catolicismo lo que era pura y simplemente el establecimiento de una Europa bajo el modelo fascista:

España quiere siempre para Europa un destino imperial, es decir una Europa unida cupularmente por la vía del Poder católico, fusionada en la vida espiritual esencialmente justa, fundamental y racionalmente justa o sea capaz de recoger cuantas empresas brotan dentro de ella con raíz histórica o nacional, si son aptas para satisfacer las aspitaciones más altas de los grupos humanos que habitan y no se oponen a su ansia irrefrenable de universalidad. A lo largo de la Historia, las apetencias hispanas por Europa, coinciden y caminan de consuno con las de otros países próceres, pero lo más alquitarado, lo que forma el núcleo de su pensamiento unitario, nos pertenece totalmente ${ }^{15}$.

Abundan menos los testimonios de expresa y entusiasta comunión con el Eje, salvo algunas muestras - por otra parte bien elocuentes- de la orientación oficial de Falange en este terreno, como lo prueba el ensayo ganador del "concurso de publicaciones de la Delegación Nacional de Propaganda", correspondiente a $1941^{16}$. Aquí se identifican los «mejores valores europeos" con los sectores «sanos» que habían tomado el poder en Alemania e Italia; en ese sentido los "valores europeos" no tendrían otro sentido que la afirmación nacionalista de unos determinados pueblos que imponen sus concepciones hegemónicas sobre los demas por la fuerza de las armas. Ese y no otro es el europeísmo de la seducción por el Eje de los primeros años de la década de los cuarenta.

Por lo demás, abundan muchos alegatos germanófilos, camuflados más o menos de europeísmo, como pone de relieve José Carlos Mainer en el terreno más estrictamente literario ${ }^{17}$. Es la producción que dibuja un panorama europeo tópico de liberalismos decadentes y que se refugia en el pasado medieval y cristiano, todo ello sazonado -en bastantes casos-de observaciones de claro corte antijudaico aunque siempre huyendo de una aceptación expresa de las teorías raciales y procedimientos nazis. Asi se puede ver - por poner un sólo ejemplo- en el libro de Carlos Sentís La Europa que be visto morir ${ }^{18}$, calificado por su prologuista, Eugenio Montes, de «libro de amor púdico al nuevo orden». Ese «amor púdico» es quizá el mejor resumen de la actitud de una parte importante de las publicaciones de estos años iniciales del réigmen, en donde la actitud pro-eje, el anticomunismo, un antisemitismo matizado y los prejuicios ante el liberalismo inglés y el cosmopolitismo francés serán los ingredientes clave

15 Ibidem.

16 Pinzón TOSCANO, A., Defensa española de la cultura europea, Ediciones de la Vicesecretaria de Educación Popular, Madrid, 1942.

17 MAINER, J. C., «La segunda guerra mundial y la literatura española: algunos libros de 1940-1955», en José Luis GARCiA DELGADO (ed), El primer franquismo. España duante la segunda guerra mundial Siglo XXI, Madrid, 1989.

18 SENTTS, C., La Etropa que be visto morir, Editora Nacional, Madrid, 1942. Prólogo de Eugenio Montes.

Hispania, LVIII/2, núm. 199 (1998) 679-701 
que muestran más que un deseo de integrarse en Europa, un desprecio por la historia de los últimos siglos del continente en contraste con la recuperación mitificada del «imperio español».

De hecho, la que será «biblia» de los afanes neoimperialistas del régimen, el libro Reivindicaciones de España ${ }^{19}$ combinaba la interpretación de la historia de España en clave nacionalcatólica y menendezpelayista con unos expresivos anhelos de dominio español en la zona del norte de Africa a costa de las posesiones francesas e inglesas. Estas recompensas territoriales que hiciera teal el anhelo imperial era la moneda de cambio que pedía Franco para consentir en la entrada en la guerra al lado de Hitler ${ }^{20}$, lo que mostraba hasta que punto el nacionalismo constituía una parte fundamental del régimen.

\section{LA EUROPA DE LA DESOLACIÓN}

El fin de la guerra mundial traerá el único momento de real peligro político para la supervivencia del régimen ${ }^{21}$. A pesar de esto, el discurso franquista no va a ser el de arrepentirse de las viejas simpatías, sino el de negar que éstas algunas vez existieran, en la mejor línea orwelliana. Eso y la afirmación constante de las raices católicas del régimen español van a ser las armas propagandísticas fundamentales en la coyuntura de 1945 y años siguientes. Esta evolución tendrá su máxima expresión en el cambio de gobierno de julio de ese mismo año 1945 , con la irrupción en el gobierno de algunas importantes figuras del catolicismo político más conservador, simbolizadas en el nuevo Ministro de Asuntos Exteriores, Alberto Martín-Artajo.

Va a ser también un tiempo de constatar la destrucción material y moral de Europa, la desolación ante los resultados de la contienda en la mayor parte del continente. Este panorama va a ser aprovechado por la publicística franquista y los instrumentos de adoctrinamiento españoles para establecer un contraste entre esa Europa destruida y desgarrada y una España que, gracias a la «sabidutía) $\mathrm{y}$ «astucias del Caudillo había quedado al margen de esa desolación. Se presentaba así como una estrategia preconcebida lo que sólo había sido el resultado de las circunstancias. De esta manera, de forma subliminal las imágenes y crónicas de una Europa en ruinas servían de reforzamiento al régimen español. Esta argumentación se sostendrá también a lo largo de los años del aislamiento internacional. Buena muestra de ello son artículos como el de Emiliano Aguado ${ }^{22}$, en donde se nos describe la mala situación de Europa, el horror, la inseguridad y un gran miedo y hondo pesimismo. A esta tarea

19 AREilza, J. M. a de, CAstiell.a, F. M. ${ }^{a}$, Reitindicaciones de España. Instituto de Estudios Políticos, Madrid, 1941.

20 PRESTON, P., Franco Caudillo de España. Grijalbo, Barcelona, 1994.

21 Sobre el periodo de aislamiento de España, vid. el imprescindible libro de PORTIIRO, F., Franco aislado. La czestion española (1945-1950), Aguilar, Madrid, 1989. (1944).

22 AGUADO, E., «Europa. El hombre y la politica», Revista de Estudios Politicos n. ${ }^{\circ} 15$

Hipania, LVIII/2, núm. 199 (1D98) 679-701 
descriptiva se dedican revistas de forma monográfica como la que ostenta el curioso nombre de Europa se muere y de la que sólo conocemos un número ${ }^{23}$. En otros libros de la época, junto a la descripción de los horrores bélicos y de los problemas de una dificultosa reconstrucción se muestra también una Europa decadente en su conjunto, especialmente los países mas asociados al liberalismo político como Gran Bretaña y Francia, como es el caso del libro de Carmen Llorca ${ }^{24} y$ en todo caso, con un gran pesimismo ante el futuro europeo ${ }^{25}$.

A partir de esta actitud pesimista sobre la situación europea, se llega, en el terteno más ligado al pensamiento, a expresar una preocupación por lo que podríamos definir en terminos de la época la "esencialidad europea», puesta en entredicho por el estallido mismo de la guerra; desde ese punto de vista, la postración material sería un reflejo de la inanición espiritual; también entonces se empieza a tener la percepción de que Europa había dejado de ser protagonista, una vez que el mundo se reorganizaba en los términos de la guerra fría, con una Europa dividida y «encajonada» entre los dos grandes bloques de poder encarnados en EEUU y la Unión Sovietica, con lo que suponía de riesgo, como muchos autores pondrán de relevancia, para el mantenimiento de una cultura propia europea. Estos temas están presentes en trabajos como los de Francisco Javier Conde ${ }^{26}$ o Carmen Llorca, especialmente en el caso del primero, ya que la segunda es mucho más superficial, aunque sea una de las primeras personas que enarbola la bandera de la integración europea como respuesta ante la "amenaza rusa»y ante el "materialismo" propio de la cultura norteamericana. Al postular unos «Estados Unidos de Europa» inauguraba una fecunda línea europeísta, aunque la autora no se plantee tal unidad sino como una defensa de la «civilización» frente a la "masa informe».

Javier Conde abordará en sus trabajos lo que ya era conocido en esos momentos como uel problema de Europa»: redefinir Europa y su papel en el nuevo contexto internacional. Conde intenta reflejar la confusión del hombre europeo, su pérdida de valores y las razones de ello, haciendo un repaso a la evolución político-social del hombre europeo desde la edad media, concluyendo que todos los cambios políticos se han basado en el terror; un terror que ha ido en ascenso y que ha marcado los grandes hitos de las revoluciones europeas. La única salida a esta situación sería íntima y humanista. Es decir, la respuesta es volver a los viejos valores del humanismo cristiano, renunciando al materialismo. La «humanización» del hombre o «rehumanización» sería la clave para superar la "depravación del europeo», inscribiendole así «en el horizonte

\footnotetext{
23 Europa se muere n. 1 (enero 1946), Editorial Mundial.

24 LIORCA, C., Europa zen decadencia?, Prensa Española, Madrid, 1949.

25 GÓMEZ ARBOLEYA, E., «Posición y ámbito del problema de Europa», Revista de Estudios Politicos, n. ${ }^{\circ} 50$ (marzo-abril 1950).

26 CONDE, F. J., Sobre Ia situacion actual del europeo, Publicaciones españolas, Madrid, 1949. Un resumen de sus tesis en CONDE, F. J., «Sohre Ia situación actual del europeo», en Revista de Estudios Politicos n. 45 (mayo-junio, 1949).
} 
del temor de Dios y de la esperanzas. Así, este nuevo humanismo, al que hace mención Pasamar ${ }^{27}$, enmascaraba la propuesta del régimen franquista como modelo espiritual para el resto de Europa. Al postularse como ejemplo, se sugería el papel fundamental de la "cruzada» en la recuperación de estos valores que parecen irremisiblemente perdidos para el resto de Europa por haberse alejado precisamente del catolicismo originario y consustancial — según esta interpretación- a la formación de Europa como unidad cultural.

Quizá lo que le faltó a Europa es haber sido plenamente fiel a sus propios supuestos. Europa pretendió más que realizó la toma de posesión de todo el hombre. Fuera de su humanismo quedaton siempre zonas que continuamente se alzan reivindicando su puesto. Este humanismo se disgregó en una capa débil de razón abstracta y en una amplia de cuño irracional. [...] Y de esta interna situación brotaron todas sus disensiones y su situación actual 28 .

Pero esta reflexión sobre «el problema de Europa» no es exclusiva de España por interés político. Los encuentros celebrados en Ginebra en 1946, en los que se aborda el tema de la unidad europea, muestran la existencia real de este pesimismo y confusión entre la intelectualidad europea, como lo atestiguan las discusiones de los asistentes, entre los que destacan Lukacs, Jaspers, MerleauPonty o Julien Benda. Las discusiones sobte la posibilidad misma de una unidad europea y sobre cuales serían sus bases serán punto de referencia para muchos ensayistas españoles.

Junto este ensayismo de élite, se intentaban propagar a través de una publicística mucho más burda algunas de estas ideas. Por ejemplo, se presenta en términos apocalípticos la «decadencia europea», contraponiéndola a la situación española de "salud espiritual». Desde esta postura cobra entonces "sentido" la existencia de una hostilidad hacia España pues sería el producto de la «envidia» existente hacia la situación española o la persistencia de una sleyenda negray sobre quien mejor encarna los auténticos "valores europeos y occidentales», como afirma Carrero Blanco trasmutado en Juan de la Cosa ${ }^{29}$. Así no puede extrañar que se postule «la cultura hispánica como factor de la restauración espiritual europea y mundials ${ }^{30}$. Lo dirá el mismo Franco:

El mundo occidental y cristiano no ha saldado aún su deuda con un pueblo que supo ofrecerle tan fuerte y trascendente partida de valores espirituales y morales. Si Europa puede un día recobrar su integridad su alma y su misión, a la cruzada española se lo deberá en primer lugar ${ }^{31}$.

27 PASAMAR AlzURIA, G., Historiografia e ideologia..., p. 92.

28 GÓMEZ ARBOLEYA, E., op. cit., p. 122.

29 COSA, J. de la [CARRERO BLANCO, L..]. España ante el mundo (proceso de un aislamiento), Ediciones Idea, Madrid, 1950.

30 NAVASCUES MORENO, B., La filosofía moderna como factor de la tragedia etropea, Librería General, Zaragoza, 1948.

31 Franco Bahamonde, F., Pensamiento politico de Franco. Antologia. Servicio Informativo Español, Madrid, 1 964, P. 432.

Heipania, LVIII/2, núm. 199 (1998) 679-701 


\section{LA RECREACIÓN DE UNA EUROPA CRISTIANA}

Sirve la cita anterior para enlazar con lo que va a ser la visión fundamental y básica de Europa en la España franquista, en el sentido de que está presente como ingrediente básico en la casi totalidad de grupos que operan en el seno del régimen. Esta visión se basa en la interpretación de la historia de Europa a partir del carácter primordial en ésta del cristianismo y singularmente, el catolicismo tomano. Según esta vision Europa fue preponderante y tuvo vitalidad en todas sus empresas en la medida que sus valores fueron fieles a los señalados por la Iglesia católica y la propia tradición cristiana que se remonta a la dominación romana y a la religiosidad medieval; cuando, a partir de la ilustración, se da una secularización progresiva de la sociedad y del gobierno y se relega la tradición, Europa se separa de su "destino" y pierde el norte que le conduce a la destrucción y postración posterior. El siglo XVIIr sería el momento en que, por mor de esta "desviación» de Europa, España se separaría de ésta para seguir fiel a sus principios de la tradición católica, si bien con grandes peligros procedentes también de los «vientos europeos», que sólo se conjuran definitivamente con el alzamiento del 18 de julio de 1936 y con la implantación del nuevo tégimen.

Esta interpretación básica, aunque, como hemos dicho, es común a casi toda la Intelectualidad franquista, corresponde fundamentalmente a las elaboraciones de núcleos católicos integristas y antiliberales aglutinados en los segundos años cuarenta y primeros cincuenta en torno a la revista Arbor, órgano del Consejo Superior de Investigaciones Científicas desde su creación en 1944, cuyo valor fundamental era el entonces joven y ambicioso Rafael Calvo Serer, secundado por profesores e investigadores afines a la empresa intelectual de Arbor: Florentino Pérez Embid, José M. ${ }^{2}$ Sánchez de Muniain, etc.

No se puede hablar, sin embargo, de monolitismo en las filas del catolicismo político español. Recordemos que junto a los grupos más fácilmente encuadrables en el integrismo de matriz opusdeísta, están los propagandistas y los ligados más directamente a la jerarquía eclesiástica a través de Acción Católica. Algunos de ellos estatían más cercanos a la actitud de un Laín o un Ridruejo; otros procedian de la CEDA, del entorno de Herrera Oria y E/ Debate; hubo además acenepistas que negaton su colaboración al régimen u otros que, más o menos timidamente, buscaban una evolución hacia una monarquía más parangonable con el horizonte político europeo de posguerra. Muchos de estos últimos se enfrentarán de manera clara al catolicismo de corte integrista, cuyos puntos de referencia eran el CSIC y la Obra. En definitiva, existían proyectos políticos diversos dentro del catolicismo político de la época, aunque coincidietan en considerar la tradición católica como pilar fundamental de la nación española. También coincidían en cierta medida en la necesidad de impedir la consolidación o, más adelante, resurgimiento de las propuestas «totalitarias» de los falangistas, que como aparato de poder estaba claramente enfrentados a las posiciones de la Iglesia y del catolicismo político en general, aunque en algunos casos se compatibilizaran las dos fidelidades.

Hi.paniu, IVIII/2, núm 199 (1998) 679-701 
La interpretación en clave católica de la historia europea y española tendrá su principal adalid en la revista Arbor, portavoz oficioso de los sectores más integristas del catolicismo franquista de la mano de su principal animador Rafael Calvo Serer ${ }^{32}$.

Será precisamente Calvo Serer y su grupo los que defiendan con mayor denuedo la interpretación menendezpelayista de la historia española y de su lugar en la historia de Europa frente a las tesis sustentadas por Pedro Laín en su libro España como problema, contestado en el trabajo de Calvo Serer España sin problemas y en una serie de artículos en la misma línea de él y de otros, mayoritariamente publicados en $A$ rbor ${ }^{33}$. Laín abogaba por una "concienca integradora» que traslucía una "conciencia en conflicto", en palabras de su cercano Ridruejo ${ }^{34}$, lo que chocaba con el esquema interpretativo basado en Menéndez Pelayo que hacía hincapié en la unidad esencial de España en torno a los valores católicos tradicionales y rechazaba toda "conciencia escindida", en una actitud intransigente frente a lo que se desviase de esta ortodoxia.

La cuestión europea estaba plenamente presente en esta polémica, en la medida en que la definición del papel de España implicaba una determinada actitud respecto al resto de Europa. En cierta medida, se estaba replanteando una vieja polémica resumida en el dilema "españolización o europeización», negado en cambio por los integristas españoles, ya que, según ellos, el debate habría sido superado por la propia guetra española, que engendró una «España sin problemas:

Estamos, en verdad, muy lejos de aquella lacerante antinomia de españolización o europeización, que fue tan cara a los hombres del 98 . Y de un modo o de otro, ha seguido preocupando o confundiendo a muchos de sus sucesores. La que Laín llama irresuelta polémica entre el progresismo antitradicional y el tradicionalismo antiactual se resuelve para nosotros en una sintesis feliz españolización en los fines y europeización en los medios ${ }^{35}$.

Una vez que la esencia de la «españolidad» ya habría sido aclarada, sólo quedaría resolver problemas concretos. Esta catolicidad intrínseca del ser español era a la vez compatible con el reconocimiento de la superioridad económica y tecnológica de Europa, explicable dado que los españoles estarían mejor dotados para asuntos del "espíritu». Así, la relación que se estableciera con Europa sería de intercambio: tecnología y mejora de unos

32 Un análisis imprescindible de esta publicación es el que se encuentra en $A \mathrm{RBOR}$ n. ${ }^{\circ}$ 479-480 (noviembre-diciembre 1985) Monográfico "40 años de Arbor: un análisis autocrítico» coordinado por Gonzalo PASAMAR.

33 CALVO SERER, R, España sit problema, Rialp, Madrid, 1949. Entre sus colaboraciones en $A r b o r$ destacan (España sin problemas», Arbor n. ${ }^{\circ} 24$ (noviembre-diciembre 1947) y CALvo SERRER, R., "Valotación europea de la historia española», Arbor n. ${ }^{\circ} 7$ (enero-febrero de 1945).

34 Díaz, F., Notas para una historia..., p. 71.

35 PÉREZ EMBID, F., «Ante la nueva actualidad del "problema de España"», Arbor, n. ${ }^{\circ} 45$ 46 (septiembre-octubre, 1949).

Hípania, LVIII/2, núm. 199 (1998) 679-701 
valores ya perdidos en el extravío moral de Europa. Precisamente esa pérdida de valores del occidente europeo había sido la causa de que España se alejara de una Europa corrupta:

El Occidente, tras la intima ruptura y las luchas de los siglos XVI y XVII, sustituyó la cultura unitaria medieval y cristinna por la abierta heterodoxia de la ilustración. Entonces la incompatibilidad de España con el desarrollo de la historia europea la obliga a aislarse de Eutopa, agudizándosce con ello su propio desmoronamiento político, cultural, religoso y social. De esta manera, lo que ha venido llamándose decadencia española viene a manifestarse más realmente como una fundamental discrepancia con la Europa moderna ${ }^{36}$.

España aparecía pues como la única conservadora de los valores europeos, es decir el cristianismo como estructura de poder que hundia sus raíces en el Sacro Imperio romano-germánico. De ahí que se diga que el camino para la europeización de España pasa por la «españolización» de Europa. España se erigía en la «reserva moral de Europa» y emblema para «los espíritus selectos de todo el mundos ${ }^{37}$. Si España había quedado aislada en los últimos tiempos era por un fenómeno pendular de la historia: «[...] lo cristiano es algunas veces negado por las oscilaciones pendulares de la cultura, y con él lo español, por su identificación con lo católico; de aquí que la cultura española siga en la cultura moderna el proceso de la cristiandad: la estimación o desestimación de ésta trae consigo la estimación o desestimación de Españas ${ }^{38}$.

El camino a seguir, para españoles y europeos, era nítido:

Sólo la fidelidad a nuestro destino --el cumplimiento de defensores de la cristiandad- hará posible nuestro resurgimiento, reintegrándonos al mismo tiempo a la historia universal, en el momento en que Europa solamente puede evitar su destrucción volviendo a las raices cristianas de su historia. El pueblo que to dio todo por mantener aquel espíritu pasa de nuevo a ser actor principal en la historia de occidente ${ }^{30}$.

Para soportar y justificar esta visión, se difundirán trabajos de determinados ensayistas extranjeros de proeedencia normalmente católico-conservadora, como Christopher Dawson, que escribe en Arbor y en la tradicionalista Punta Europa ${ }^{40}$; Wilhelm Ropke ${ }^{41}$ o el emigrado rumano Vintila Horia, que se afinca-

36 CALVO SERER, R., "Una nueva generación española», Arbor n. 24 (noviembrediciembre, 1947), p. 339.

37 CALVO SERER, R., "Valoración europea de la historia españolam, Arborn. ${ }^{\circ} 7$ (enerofebrero de 1945), pp. 44 y 45.

38 Ibidem, p. 44.

39 CALVo SERER, R., "Una nueva generación española», Arbor n. 24 (noviembrediciembre, 1947 ), p. 344 .

40 Su libro más influyente editado en España es DAwSON, Ch., Hacia la comprensión de Europa, Rialp, Madrid, 1953.

41 Se puede destacar su ROPKE, W., (Europa desde fuera. Meditación sobre el ente y los limites de un continente), Arbor, n. ${ }^{\circ}$ 201-202 (septiembre-octubre, 1962).

Hingania, LVIII/2, núm. 199 (1998) 679-701 
ría definitivamente en la España de Franco. En esta difusión tendrá un importante papel la editorial Rialp con su colección «Biblioteca del pensamiento actualy, así como Editora Nacional en su colección "O crece o muere", todo ello en manos de hombres cercanos a la Obra, principales valedores de esta visión integrista de la historia de Europa.

Esta interpretación va a estar presente también en los representantes del tradicionalismo, a veces expuesta de una manera más agresiva y polémica, como lo muestra Vicente Marrero en su libro La guerra de España y el trust de cerebros ${ }^{42}$ y en la revista de pretendido talante europeísta y dirigida por él mismo Punta Europa, creada en enero de 1956.

La interpretación católico-integrista tenía una perfecta coherencia con la postura oficial del régimen, al encarnar en la «cruzada» el triunfo de las ideas de Menéndez Pelayo, afirmando así el carácter católico del régimen y entroncándolo - bien que forzadamente - con una influyente corriente ideológica y política en Europa, el catolicismo político. Calvo Serer irá, sin embargo, más lejos en sus pretensiones e intentará formular un proyecto político específico a partir de estos planteamientos. Será la fótmula urestauracionista» también conocida con el nombre de «Tercera fuerza» y que postulaba la implantación de un régimen enraizado en la «doctrina política de la tradición española: monarquía no cortesana, sino tradicional, hereditaria, antiparlamentariạ y descentralizadas ${ }^{43}$.

La consideración del catolicismo como ingrediente fundamental y definitorio del «ser español» y por lo tanto, base de cualquier régimen que en España quiera implantarse hará fortuna. Franco lo repetirá en bastantes ocasiones, al referirse a la existencia de diferencias "espirituales» con Europa o al subrayar la importancia de la aportación española a la historia europea ${ }^{44}$. Esta visión menendezpelayista de la historia de España y la ecuación «europeísmo igual a cristianismo" estará presente también en los libros de texto ${ }^{45}$, en un intento de integrarse en el inconsciente colectivo español.

\section{EUROPA COMO SOLUCIÓN AL «PROBLEMA DE ESPAÑA *}

Habían sido quizá los más lúcidamente totalitarios (en el sentido de más afines intelectualmente a lo que suponía un proyecto fascista), y fueron también los que mostraron una mayor flexibilidad intelectual en su evolución posterior, demostrada por su progresivo alejamiento del régimen; algunos, con gran rapidez, como Ridruejo, tras ostentar importantes cargos y otros, como Lain o To-

\footnotetext{
42 MARRERO, V., La guerra española y el trust de cerebros, Editorial Punta Europa, Madrid, 1961.

43 CALVo SERER, R., España sin problema, Rialp, Madrid, 1949, p. 171.

44 Franco BnimMONDE, F., Pensamiento politico..., pp. 441-446.

45 VALLS, R., "Ideología franquista y enseñanza de la historia en España 1938-1953», en FONTANA, J, España bajo el franquismo. Departamento de Historia Contemporánea de la Universidad de Valencia/ Crítica, Barcelona,1986.

Hispania, LVIII/2, núm. 199 (1998) 679-701
} 
var, manteniendo una postura más escéptica respecto al régimen, aunque participando en éste junto a los sectores que buscaban cierto aperturismo o evolución.

Quizá la posición que ocupan estos hombres - Pedro Laín, Antonio Tovar $y$, más singularmente, Dionisio Ridruejo- en el panorama político del franquismo de los últimos años cuarenta y primera década de los cincuenta está relacionado con la agresividad de las formulaciones integristas. De hecho, las posiciones de ambos grupos se perfilan en el debate mutuo; un debate que derivará en abierta lucha política con motivo de la puesta en práctica de alguna de las ideas «integradoras» desde el Ministerio de Educación Nacional presidido por Ruiz-Giménez, cuando Laín y Tovar ocupen sendos rectorados y se consiga la vuelta de los primeros exiliados de adscripción liberal a sus puestos universitarios. La condena virulenta por parte de Calvo Serer de esta política acabatía con la expulsión de éste de la dirección de Arbor en 1953.

Pedro Laín va a ser el mas destacado ensayista y, por lo tanto portavoz del grupo, que aunque muy personalizado, eran un símbolo y un punto de referencia para muchos univetsitarios e intelectuales ${ }^{46}$. Un grupo que partía de la aceptación del 18 de julio, pero que mantenía una interpretación no integrista de la historia española, lo que se traducía en buscar unos diferentes contenidos para el régimen, buscando, eso sí, su consolidación. Así, aunque se reconocía la aportación de pensadores como Menéndez Pelayo - del que Tovar prologará y realizará una antología ${ }^{47}$ - no se le otorgaba el papel fundamental que le daban los integristas como superador de la división de España en dos grandes bloques intelectuales y políticos. De hecho, la tesis de España como problema, es que España tenía pendiente aún la integración de la España liberal y progresista, derrotada en la guerra civil. Esta necesaria sintesis se resumía en lo que Ridruejo llamaría "conciencia integradora». Mientras éstos intentaban integrar las diferencias dentro de un régimen más "comprensivo", el catolicismo político contrarreformista, con Calvo Serer a la cabeza, intentaba anular esas discrepancias por la vía de la intransigencia o la uexclusión». De esta manera se perfilaba el debate entre «excluyentes» y "comprensivos» característico de los primeros años de la década de los cincuenta.

Se ha buscado como antecedente de esta postura la actitud de la revista $E_{s-}$ corial, en la inmediata posguerra, con su ya famoso llamamiento de su primer editorial:

Convocamos aquí, bajo la norma segura y generosa de la nueva generación a todos los valores españoles que no hayan dimitido por entero de tal condición, hayan servido en éste o en el otro grupo — no decimos, claro está, hayan servido o no de auxiliadores del crimen ${ }^{48}$.

46 Su libro referencial en esta polémica será LAÍN ENTRALGO, P., España como problema, Seminario de Problemas Hispanomericanos, Madrid, 1949.

47 TOVAR, A., La concieneia eapañola, EPESA, Madrid, 1948.

48 Escorialn. ${ }^{\circ} 1(1940)$. 
En este contexto, el tema de Europa era una forma de reproducir el debate, al plantearse la europeización de España como una forma de recuperación e integración de una importante parte de la tradición filosófica y política del liberalismo, y por lo tanto suponía una confrontación con los que veían en la aproximación a Europa precisamente un riesgo de pérdida de unos «tecuperados» valores hispanos, admitiendo sólo la posibilidad de una integración en la medida que Europa empezara a participar de la cosmovisión integtista española.

Quizá el mayor valor de estas tesis de Laín y sus compañeros era la consideración de Europa como redimidora de viejos problemas españoles, como la solución y la esperanza de viejas carencias históricas, idea y sentimiento que calaría hondamente en la sociedad española. Esta línea de razonamiento la encontraremos mucho después, cuando un Manuel Fraga ${ }^{49}$ aboga por europeizar España ante la existencia de un "problema de España), aunque eso debiera ser compatible - no podía ser de otra manera- con el mantenimiento de la especificidad política española.

Esta semilla de «liberalización política» se ve desarrollada plenamente en Dionisio Ridruejo, hombre que va convertirse en un serio europeísta y auténtico adelantado del modelo de integración europea que se seguirá por parte de la Comunidad Europea, muy crítico con las interpretaciones conservadoras y «medievalizantes» de la unidad europea que se elaboraban en España ${ }^{50}$. Su modelo de integración debía conjugar la mejor tradición racional y liberal europea, cultivando la democracia y la libertad, y fundamentando un orden basado en criterios morales y de dignidad de la persona y los pueblos; una Europa solidaria y abierta al resto del mundo. Europa era también una esperanza de «normalización’ del régimen franquista dentro de un matco democrático, dejando de lado «fórmulas de mesianismo y terron en palabras del mismo Ridruejo. Ridruejo, participará, coherente con esta actitud, en la reunión del Movimiento Europeo de 1962 en Munich, como recuerda Julián Gorkin ${ }^{51}$.

\section{FL ENTUSIASMO EUROPEÍSTA}

El franquismo no se va a caracterizar solamente por elaboraciones ideológicas de tipo nacionalista conservador o por pretensiones voluntaristas y aisladas; en la sociedad de la época vemos también aparecer, especialmente en los años cincuenta, una serie de iniciativas de nítido corte europeísta. Normalmente, se trataba de núcleos inquietos que por tradición cultural e interés humano buscaban la integración de España en Europa y que seguirán con enorme interés el proceso de acercamiento europeo, pasando a format parte del llamado

49 FraGa IrIBarne, M., «Forma política de la unidad european, Arbor n. ${ }^{\circ}$ 201-202(septiembre-octubre 1962).

50 RIDRUEJO, D., «La Europa que puede acontecem, presentación en M. BORN y F. GiLSON, Europa y el mundo de boy. Rencontres Internationales de Gènève 1957, Guadartama, Madrid, 1959.

51 GORKIN, J., «Mi encuentro hispano-europeista con Dionisio Ridruejo», en Dionisio Ridruejo. De la Falange a la oposición, Taurus, Madrid, 1976.

Higania, LVIII/2, num. 199 (1998) 679-701 
«movimiento europeo». Detrás de estos grupos, que aparecían aislados en diversos lugares del país, se escondían a veces intereses políticos conscientes (la captación de descontentos, la pantalla legal de un movimiento de oposición al régimen) y, a veces, menos conscientes (lo que se buscaba de forma difusa y vaga era una renovación de los horizontes políticos, culturales y sociales).

Estos grupos europeístas van a darse de forma autónoma aunque en muchas ocasiones se utilicen también los propios canales que brindaban las distintas secciones $\mathfrak{u}$ organismos del Movimiento. De estos canales oficiales se aprovechará especialmente la juventud, encuadrada obligatoriamente en ellos. De esta manera nos encontramos que revistas como Laye, financiada por la Delegación Provincial de Educación de Barcelona y que agrupaba a lo que luego sería lamada «escuela de Barcelona», mostraban un activo europeísmo; que las actividades del SEU relativas a viajes al exterior que potenció la jefatura de Jorge Jordana sirvieron para que estos jóvenes conocieran la realidad europea más próxima y respiraran «un soplo de aire fresco». Asimismo, en el seno del Frente de Juventudes, SEU y demás instancias juveniles adscritas al Movimiento surgen revistas orales, seminarios y encuentros de diverso tipo, en donde la preocupación europea es lo fundamental. Un europeismo muy poco politizado de forma expresa, pero con una gran carga de rechazo del régimen: en la medida en que se ansiaba la apertura a Europa y la integración plena de España en ésta se deseaba la modificación del régimen español y la desaparición de unas trabas y limitaciones políticas y vitales inexistentes en el a veces demasiado mitificado en estos años mundo europeo occidental. Europa se perfilaba para esta generación de los cincuenta como una auténtica alternativa política, social y vital al franquismo.

La preocupación por el proceso de construcción eutopea se puede constatar también en las publicaciones oficiales u oficialistas a las que nos hemos teferido con anterioridad como Arbor o Revista de Estuios Politicos, donde se incluyen artículos fundamentalmente descriptivos sobre las características y evolución del movimiento europeo, el análisis de las primeras instituciones europeas, etc. Estos artículos florecerán de manera especial con ocasión de la solicitud de la adhesión de España al Mercado Común, aunque ya hay estudios de este tipo con anterioridad ${ }^{52}$. Casi todos ellos estaban presididos por un espíritu favorable a esta integración europea, como única forma para muchos de frenar el peligro económico y cultural de la pujanza estadounidense (Azaola, 1951, 475). Arbor mostrará también en sus contenidos un creciente interés por la actualidad política europea, incorporando, a partir del $n^{\circ} 17$, una sección llamada «información cultural del extranjero». En septiembre de 1962, se le dedicará al tema de la integración europea un número monográfico. La Revista de Estudios Políticos, que siempre había prestado atención al «problema

52 Por ejemplo el de AZAOLA, J. M. de, «el "movimiento europeo" hoy", Arbor n. " 67-69 (julio-agosto 1951) o el de MENSUA, S., «Europa entre la crisis de postguerra y la integración económicas, en Nuestro Tiempon. ${ }^{\circ} 94$ (abtil, 1962).

Hípania, LVIII/2, núm. 199 (1998) 679-701 
de Europa», hará un esfuerzo progresivo por proporcionar información sobre aspectos culturales, jurídicos y sociales del exterior europeo, especialmente en el terreno de las relaciones internacionales. En sus «Noticias de librosin se $i b a$ a recoger una parte significativa de la bibliografía internacional sobre el tema de la unidad europea. En el mismo Instituto de Estudios Políticos se pondrá en marcha un Seminario de Europa en el curso 1949-50. Estos aportes sirvieton en gran medida pata que el español con inquietudes europeístas se pusiera al día de la marcha del proceso de integración en Europa.

Ya en los inicios de la década de los sesenta aparecen otros estudios de carácter oficial, normalmente debates o encuentros sobre la problemática europea, una vez establecida la ineludibilidad de la convergencia española hacia sus vecinos europeos ${ }^{53}$. Muy pocos rechazatán esta inclusión abiertamente y los que lo hagan serán una minoría frente a una mayoría que veía el proceso como positivo, aunque para defenderlo se recurriera al magisterio papal ${ }^{54}$.

Con todo, y como hemos dicho, fueton iniciativas extraoficiales -aunque se desarrollaran en el seno del propio oficialismo en ocasiones- de muy diverso tipo y con base juvenil muchas veces, las que se encargaron de emparentar en el inconsciente colectivo de los españoles la noción de Europa con las de libertad y progreso. En esto influyó el catolicismo político posterior a 1954 y aglutinado en torno a los sectores más europeístas de la $\mathrm{ACNdP}$, que darán lugar al nacimiento de una Asociación Española de Cooperación Europea, como dice Tusell ${ }^{55}$, pero sin duda el mayor aporte es el que se plasma en las iniciativas de base.

No se explica de otra manera la importancia que el tema europeo alcanza en revistas del oficial Sindicato Español Universitario como Alcalá o La Hora, e incluso Theoria, que nacerá del mismo tronco de Alcalá ${ }^{56}$. O el vigor de la vida cultural de Colegios Mayores y agrupaciones culturales constituidas a su sombra, que hacen del europeismo una preocupación creciente, como señala la existencia de numerosas revistas orales y seminarios sobre el tema, a veces de escasa prolongación enel tiempo, pero de fuerte impacto. La misma revista Laye, pese a su origen oficial en la financiación y dirección, marcará un estilo de compromiso progresista en la política y la literatura en los años cincuenta y sesenta de Barcelona, auténtica abanderada de la silusión europeas (Bonet, 1988,

53 Podemos citar el sgnificativo Estudios sobre la integración europea. Seminario de Estudios Internacionales "IJordan de Asson (CSIC) de la Universidad de Zaragoxa, Universidad de Zaragoza, Zaragoza, 1960. Entre los trabajos que destacan CAPELO MARTínEZ, M., «El Mercado Común Europeo: Fundamentos y propósitos", Arbor n. ${ }^{\circ}$ 201-202 (septiembre-octubre 1962); LARRAZ, J., «La federación europea», Arbor, n. ${ }^{\circ}$ 201-202 (septiembre-octubre, 1962); PARDOS PÉREZ, J.L., «El Consejo de Europas, Arbor, n. ${ }^{\circ}$ 201-202 (septiembre-octubre, 1962).

54 Martín ARTAjo, A., "La Unidad de Europa en el pensamiento de Pio XII", Arbor, n. 159 (marzo, 1959).

55 TUSELL, J., La España de Franco. El poder, la oposición y la politica exterior durante el franquismo, Historia 16, Madrid, 1989.

56 RUIZ CARNICER, M. A., E/ Sindicato espaniol Universitario (SEU) 1939-1965. La socialización politica de la juventud universitaria en el franquismo, Siglo XXI, Madrid, 1996.

Hippania, LVIII/2, núm. 199 (1998) 679-701 
39). El mito europeo, como dice Laureano Bonet «no se agota en un simple ejercicio intelectualista: es, ante todo, experiencia vital, profundamente interiorizada en estos escritores aún inmaduros, anhelantes por "huir" a Europa, sumergirse en su más cálida pulpa cultural, sorber los zumos prohibidos, en España, de la libertad política, moral, etótica) ${ }^{57}$. Esta observación se podría extender a una significativa parte de la juventud española de la época.

Esta salida al exterior, la búsqueda de nuevos vientos y paisajes estaba muy ligada a la necesidad de un nuevo marco referencial ante la mediocridad asfixiante de la España franquista. La posiblidad de llevar a la práctica estos afanes estaría también telacionada con la política de sapertura» del ministro Ruiz $\mathrm{Gi}$ ménez al frente de Educación Nacional en la primera mitad de los cincuenta, que explica tambíen el protagonismo y la inquietud del medio universitario en esos años.

Podriamos citar muchas otras iniciativas. Quizá sea significativo el referitse a la aparición de un Centro Universitario Europeísta en Granada a fines de los años cincuenta en el seno del SEU granadino, que cuenta con emisiones de radio, proyectos como la edición de una revista mensual (Europa) y un lenguaje atrevido para la época, apostándo por un marco federalista y europeísta y atacando la cerrazón económica y social de España ${ }^{58}$. Otros muchos ejemplos y no sólo universitarios se pueden dat; en 1962, se celebra, con un artículo en $A r$ $b o r$, los diez años del Instituto de Estudios Europeos de Barcelona, por ejemplo ${ }^{59}$.

Europa será tambien aglutinante para las actividades políticas de oposición al régimen. Atraía colaboradores $y$, a la vez, servía de «fachada» para estas actividades. De ahí el nombre de Asociación Funcionalista Europea como cobertura para la creación en la práctica de los primeros núcleos organizados de marxismo intelectual más o menos definido, bajo el patronazgo de Enrique Tierno Galván ${ }^{60}$.

El europeísmo era crecientemente semilla de un antifranquismo militante y político, de forma mas abierta y clara a partir de 1962, tras la reunión de $\mathrm{Mu}$ nich. A partir de ese momento, todas las propuestas antifranquistas eran europeístas y todo europeismo contenía, de una manera más o menos definida, un rechazo del régimen existente en España.

\section{LA EUROPA DE LOS TECNÓCRATAS}

Los hombres que se han venido motejando como "tecnócratas" en la historiografia sobre el franquismo son los protagonistas de la última fase del perio-

57 BONET, L, La revista Laye. Estudio y antología. Peninsula, Barcelona, 1988, pp. 39 y 40.

58 Centro Universitario ewropeista. Granada. Curso 1957-1958. Granada, 1958.

59 GarCía P., CORREDERA, E., “El Instituto de Estudios Europeos", Arbor n." 201-202 (septiembre-octubre 1962).

60 Tierno Galván, E., Cabos sueltos, Bruguera, Barcelona, 1981.

Hispania, LVIII/2, núm. 199 (1998) 679-701 
do que estudiamos. Este grupo, que tiene como punto de referencia la producción ensayística de Gonzalo Fernández de la Mora, introductor en España de las tesis de Daniel Bell sobre el «fin de las ideologías», comparte en gran medida la interpretación del "problema europeo» del integrismo ultraconservador menendezpelayista. Pero su propia visión de las necesidades del Estado y su pragmatismo hará que considere algo ineludible la integración de España en el sistema económico europeo. Estos hombres percibían que para incorporar a España al capitalismo mundial, entonces en una situación de auge continuado, era necesaria esa integración; también en el aspecto político, el más delicado, y el que finalmente impedirá la coronación del proceso de normalización exterior, que había conocido sus primeros éxitos a partir de 1950.

El europeísmo de este influyente sector, que había desplazado a los católicos de viejo cuño y a los falangistas, va a ser diferente respecto a etapas anteriores y va a estar marcado más por neeesidades puramente téenieas que por otras eonsideraeiones.

A partir de este momento, y con todos los recelos polítieos e ideológicos imaginables, la vocación europea de España iba a hacerse obvia, como se pone de manifiesto en la nueva dirección de la diplomacia española, hasta entonces muy centrada aún en las relaciones con Hispanoamérica, siempre a nivel poco más que retórico, o proclamando la vigencia del viejo «bloque peninsular», como ponía de manifiesto el propio Martín Artajo en fecha tan avanzada como $1958^{\circ 1}$.

En cualquier caso, esta Europa del capitalismo integrador entra también en la cultura franquista, al formar parte de una determinada visión de un influyente sector que suponía un discurso distinto sobre Europa, aunque su propósito fuera también el de consolidar las estructuras del franquismo.

\section{EL MIEDO A EUROPA}

A lo largo de todo este período 1939-1962 se puede decir que late en los distintos grupos políticos del régimen, especialmente los mas cercanos a las posturas oficiales, un gran "tmiedo» a Europa. Miedo que reviste formas muy diversas. Miedo, sobre todo, a perder algunas de las señas de identidad que parecian ser patrimonio de la España tradicional y que afectaban a su estructura económica, al marco político, a la convivencia social y al propio mundo intelectual.

Algunos intentarán superar este miedo conjurando figuras useguras» del europeísmo, como el propio Papa; otros ponían como condición para el acercamiento a Europa que ésta reconociese como pauta de su integración las ideas de los sectores más integristas y recalcitrantes del catolicismo hispano; otros, lisa y llanamente, eran conscientes de que abrir las puertas a Europa suponía la

61 Martín ARTAjo, A., "Las constantes de nuestra política exterion, Afbor, n. 151-152 (julio-agosto, 1958).

Hipania, LVIII/2, núm 199 (1998) 679-701 
desaparición del régimen franquista, por lo que se oponían a este proceso de «normalizacióny de España en su contexto europeo. De hecho, cuando los tecnócratas proclamen la inevitabilidad de esta convergencia progresiva, se seguirá manifestando, con más vigor aún, el odio nunca superado a unos regímenes a los que se despreciaba por democráticos y de los que se temía la posible «contaminación’ de los valores "hispánicos"): lo que había que hacer era llevar éstos al resto de naciones europeas. Este será el sentido de numerosas declaraciones de Franco:

Hemos de considerar que si un día pudimos encerrarnos dentro de nuestras fronteras y vivir nuestra propia vida, hoy nos es indispensable la relación con el exterior; nuestra vida económica se basa en el intercambio comercial con otros países y los peligros que a Europa acechan también a nosotros alcanzan; pero abrir las ventanas al exterior no quiere decir que nos dejemos invadir por sus aites viciados, sino todo lo contrario: el proclamar a los cuatro vientos nuestras verdades, nuestro óptimo estado de salud nacional y nuestra buena voluntad para entendernos y dialogar con todos los pueblos ${ }^{62}$.

Sentado que en la parte económico-social caminamos hacia las mismas metas, nuestra diferencia profunda con Europa no está en lo material, sino en lo espiritual. Nosotros entendemos que lo que caracteriza y da vida a nuestra civilización occidental son los valores del espiritu; que toda la sociedad se vendria abajo si aquellos valores no la alumbran, y en la defensa de todo esto es en lo que tristemente nos encontramos más distanciados ${ }^{63}$.

Este miedo tiene una razón fundamentalmente política, aunque habrá también quienes muestren su inquietud acerca de las dificultades económicas que implicaría una rápida inclusión de España en un mercado industrial y comercialmente mucho más desarrollado que el español ${ }^{64}$. Con todo, el miedo seguía radicando en el paso de ese libetalismo económico al liberalismo político; el resultado sería la destrucción del «régimen español actuab):

La unión política de España a una Federación de países dirigidos por tales petsonalidades [los socialistas y liberales europeos] tendrá una consecuencia inevitable: la caída de su actual sistema político y la vuelta al régimen de partidos, a las luchas interiores, a las elecciones falseadas y a la paralización de su resurgimiento ecomómico, como ya ocurrió antes de 1936 y, en fin significaría que la libertad política que se ganó para España a costa de grandes sacrificios se perdetía pasando nuestro país a ser un país satélite de los países centroeuropeos ${ }^{65}$.

62 Franco Bahamonde, F, Pensamiento politico..., pp. 440.

63 Ibidem, p. 441.

64 FIGUEROA, F. de, «La política de desarrollo económico de España frente a la integración europeas, Arbor n. ${ }^{\circ}$ 201-202 (septiembre-octubre 1962).

65 París Eguilaz, H., (España y el movimiento de integración europeas, Arbor, n. ${ }^{\circ} 201$ 202 (septiembre-octubre, 1962).

Hàponia, LVIII/2, núm. 199 (1998) 679-701 
La alternativa a Europa para estos sectores era la reconstitución de una abandonada "comunidad iberoamericana» cuya cabeza sería España. No había, sin embargo, otra opción que la integración, aunque a veces la ceguera política existente en ciertos ensayistas era una muestra de hasta qué punto el franquismo como «cultura», es decir, como cosmovisión de la sesencia» de España y de su papel en el mundo era incompatible con la plena europeidad del país. De esta manera, en los años cuarenta y cincuenta e incluso avanzados los sesenta se seguirá cultivando un desprecio olímpico frente a las democracias europeas, insistiendo en la presentación del régimen franquista como una avanzadilla de un futuro aún no asumido por la cortedad de miras de la "partitocracia» europea, en vez de reconocerse como una residual muestra de un pasado superado en todos los sentidos para el resto de Europa. Sólo de esta manera se comprenderi textos como el que sigue, en el que se postula a la familia española como «esquema de represcntación política» alternativo al régimen de partidos dentro de la democracia «orgánica» del régimen:

Volvemos a lo de antes: que acaso esta formulación político-cristiana no se «estiles, no se lleve por ahi. Pero lo que sí puedo asegurar es que cuando tenemos ocasión de indicar a los expertos y sociólogos sobre la fórmuja de representación orgánica a través de la familia, se quedan sorprendidos, porque es lo que ellos en el fondo desean [...]. Tal vieja fórmula de representación orgánico-política-familiar queda en pie ante una intergración europea. Estamos seguros de que en Europa llama la atención y que puede ser también un ejemplo más lo que la familia española puede aportar a la integración europea misma ${ }^{66}$.

Mantener la «peculiaridad política española» va a ser la consigna a principios de los sesenta, igual que lo fue en los inicios del régimen; esto chocaba frontalmente con el pretendido europeismo oficial que buscaba además presentar a España como una democracia distinta o con mecanismos más «avanzados». Esta contradicción restaba toda credibilidad a los actos vagamente europeistas que como forma de subrayar la petición de adhesión española se van a dar, singularmente en 1962 (un buen ejemplo es el curso de la Universidad Internacional Menéndez y Pelaýo que tendrá lugar en el verano de 1962, como réplica a la reunión del Movimiento Europeo) y que demostraban la imposibilidad de hacer compatible la postulación de dogmas políticos y religiosos, esto es, una artificial primacía de «los valores de orden espiritual» y sobre todo la defensa de la existencia y perduración del régimen, con una equiparación a todos los niveles con los países más desarrollados de Europa ${ }^{67}$.

En contraste, tenemos un impulso europeísta crecientemente importante no sólo en la oposición del exilio o en la ménos articulada del interior, sino en unos ciudadanos que a través de organizaciones culturales, religiosas, educati-

66 LÓPEZ MEDEL, J., «La familia española ante la integración europea», Arbor, n. ${ }^{\circ}$ 201202 (septiembre-octubre, 1962).

67 Europa a la vista. Delegación Nacional de Prensa, Propaganda y Radio del Movimiento. Departamento de Publicaciones. Gabinete de Estudios, Madrid, 1963, p. 505.

Hispania, LVIII/2, num. 199 (1998) 679.701 
vas, etc. fueron viendo el europeísmo - - a veces un mero sentimiento- como una alternativa al régimen franquista. Europa era para estas personas una esperanza y no una amenaza como para la mayor parte de la élite franquista, salvo una parte lo suficientemente generosa y abierta como para ver también en la construcción europea el mejor camino para la superación de los problemas internos. De hecho, se podría concluir que el movimiento desencadenado el 18 de julio era esencialmente antieuropeo ya que intentaba frenar la transformación de España en un país democtático y avanzado. 